Student Experiences with Diversity at Liberal Arts Colleges:

Another Claim for Distinctiveness

\author{
Paul D. Umbach \\ Indiana University Center for Postsecondary Research \\ 1900 East $10^{\text {th }}$ Street \\ Eigenmann Hall, Suite 419 \\ Bloomington, IN 47406-7512 \\ pumbach@indiana.edu \\ Phone: 812.856.3004 \\ George D. Kuh \\ Indiana University Center for Postsecondary Research \\ 1900 East $10^{\text {th }}$ Street \\ Eigenmann Hall, Suite 419 \\ Bloomington, IN 47406-7512 \\ kuh@indiana.edu \\ Phone: 812.856.5824
}

Paper presented at the $43^{\text {rd }}$ Annual Forum for the Association for Institutional Research, 2003, Tampa, FL

Accepted for publication in Journal of Higher Education 


\section{Abstract \\ Student Experiences with Diversity at Liberal Arts Colleges: \\ Another Claim for Distinctiveness}

This study explores the relationship between organizational and individual characteristics and diversity-related experiences at liberal arts colleges. Compared with their counterparts at other types of institutions, students at liberal arts colleges report more experiences with diversity. In addition, this study also finds that diversity experiences are positively related with a variety of student outcomes. 


\section{Student Experiences with Diversity at Liberal Arts Colleges:}

\section{Another Claim for Distinctiveness}

Compelling arguments are coming from all quarters that diversity-related experiences benefit individual students, institutions, and society at large. Administrators (Bok, 1982; Rudenstine, 1996) and scholars (Astone \& Nunez-Wormack, 1990; Duster, 1993; Gurin, 1999; Hurtado, Milem, Clayton-Pedersen, \& Allen, 1999; Milem \& Hakuta, 2000; Rudenstine, 1996, 1996; Tierney, 1993) are on record as endorsing the positive educational effects of diversity on campus. So far, the evidence seems to suggest that diversity enhances the educational experiences of all students. However, we are only beginning to understand the relationship between diversity and student experiences while in college.

Gurin (1999) argued that a diverse student body creates a unique learning environment that leads to increased probability that students will interact with peers from different background. Hurtado et al. (1999) suggested that diverse peers in the learning environment could improve intergroup relations and mutual understanding by challenging students to refine their thinking and enriching the dialogue between students (Duster, 1993; Sleeter \& Grant, 1994). Students who interact with people of different races other than their own learn about some of the realities of the multicultural world in which they will eventually be living and working (Astone \& Nunez-Wormack, 1990; Tierney, 1993). These interactions, in turn, explain in part why students who report more diversity experiences show greater relative gains in critical and active thinking (Gurin, 1999; Pascarella, Edison, Nora, Hagedorn, \& Terenzini, 1996). Experience with diversity also appears to be positively associated with retention rates and degree aspirations (Chang, 1999), more frequent participation in community service (Bowen \& Bok, 1998; Gurin, 1999), and higher levels of civic engagement, cultural awareness, and commitment to improving 
racial understanding (Milem, 1994). Finally, diversity experiences seem to favorably influence overall satisfaction with the college experience and perceptions of the campus climate (Astin, 1993; Chang, 1999, 2001; Milem \& Hakuta, 2000).

This brief summary suggests that diversity experiences are not only related to desired substantive outcomes of college, but they also shape the way students think about themselves in relation to others, the nature of the activities in which they engage, and the value they place on attitudes toward others and their skills and competencies in working with different types of people during and after college (Gurin, 1999). That is, as a result of experiencing diversity in college, students learn how to work effectively with others and how to actively participate and contribute to a democratic society. Moreover, through engaging with people from different backgrounds and with different life experiences, students are adding to the foundation of skills and dispositions that is essential for living a productive, satisfying life after college in an increasingly multicultural world. Thus, the very act of experiencing diversity during college helps students develop the habits of the mind and heart that enlarge their capacity for doing so after college (Kuh, 2003; Shulman, 2002).

\section{$\underline{\text { Forms of Diversity Present on College Campuses }}$}

Three forms of diversity exist to varying degrees on college and university campuses that potentially influence the way students think and behave (Chang, 2001; Chang, 2002; Gurin, 1999; Milem \& Hakuta, 2000). The first, structural diversity refers to the numerical representation of students from different racial and ethnic groups in the student body (Hurtado, Milem, Clayton-Pedersen, \& Allen, 1998; Hurtado et al., 1999). The greater the number of students from different backgrounds, the more likely it is that a student will have an opportunity to interact with someone from a different race or ethnic background. In addition, a critical mass 
of students of color is important in creating an environment that uses diversity to enhance learning processes.

A second type of diversity involves the number and nature of diversity-related initiatives that colleges and universities make available. These include among others required multicultural or diversity courses (often as part of the general education component), elective ethnic studies courses, cultural awareness workshops offered during orientation and throughout the year, and cultural centers. While demographic shifts or changes in the structural diversity of campuses frequently stimulate the creation of these efforts (Chang, 2001), some colleges and universities make these opportunities available primarily because their campus lacks racial and ethnic diversity.

The third form of diversity, diversity interactions, is represented by students' exchanges with racially and ethnically diverse people as well as exposure to diverse ideas, information, and experiences. Social psychologists claim that the more interaction one has with others who hold different views, or the more one learns about various aspects of human diversity, the more likely it is that one will be challenged to think and respond in novel ways. For example, people who interact with more complex social structures exhibit a heightened sense of individuality while simultaneously showing a more complex attentiveness to the social world (Coser, 1975). Gurin (1999) contends that racially and ethnically diverse learning environments provide the types of complex social structures that stimulate the development of active thinking processes.

These three forms of diversity are not mutually exclusive. In fact, students often learn the most about diversity in its many forms not from classes or workshops, but through interacting with others whose views and cultures differ from their own. Moreover, while diversity-related initiatives benefit students who are exposed to them-even on campuses that are racially and 
ethnically homogeneous - their impact on students can be more powerful on campuses that have greater structural diversity (Chang, 2002). In sum, while each form of diversity can confer significant positive effects on educational outcomes, the impact of each is multiplied by the presence of the other types of diversity (Chang, 1999, 2000, 2002; Gurin, 1999; Hurtado, Milem, Clayton-Pedersen, Allen, 1998, 1999). Conversely, the impact of each form of diversity is diminished in settings where the other forms are less prevalent (Milem \& Hakuta, 2000). What Other Institutional Conditions Foster Experiences With Diversity?

The evidence of the impact of diversity on student learning and development is very promising. At the same time, we know relatively little about the factors and institutional conditions that promote and enhance students' experiences with diversity. Virtually all types of colleges and universities assert the value and promise of exposing students during college to all forms of human diversity (Alger, 1997). But do the benefits of diversity extend equally to students in all types of institutions?

Hu and Kuh (2003) found that students in private institutions more frequently interacted with students from different backgrounds and that students at large doctoral-extensive universities and liberal arts colleges had more experiences with diversity than their counterparts at other types of institutions. It is not surprising that students at large universities would have more exposure to diversity, given that these institutions typically enroll more students from different racial, ethnic and cultural groups. Somewhat unexpected is that students at smaller liberal arts colleges would report equally frequent experiences with diversity. Historically, small liberal arts colleges have claimed to have distinctive missions, especially when compared with large public universities (Clark, 1970; Kuh, Schuh, Whitt, \& Associates, 1991; Townsend, Newell, \& Wiese, 1992). But they also tend to be located in rural and less racially diverse 
locations. Even so, it appears that a distinctive dimension of contemporary liberal arts colleges is their ability to expose students to diversity in educationally purposeful ways. How they do this is not clear.

Purpose

This study examines the nature of student experiences with diversity at liberal arts colleges. Specifically, three questions guide the investigation.

1. How do students at liberal arts colleges compare with their counterparts at other types of institutions in terms of their diversity-related experiences?

2. What organizational factors and conditions are related to diversity experiences at liberal arts colleges?

3. What are the relationships between diversity experiences at liberal arts colleges and other educationally purposeful activities and outcomes?

\section{Data Source}

Data for this study come from the National Survey of Student Engagement. The NSSE is an annual survey of first-year and senior students that measures the degree to which students participate in educational practices that prior research shows are linked to valued outcomes of college (Chickering \& Gamson, 1987; Kuh, 2001).

The NSSE survey instrument, The College Student Report, asks students about their experiences in four areas: (1) The amount of time and effort devoted to various in class and out of class activities, (2) participation in enriching educational activities (e.g., study abroad, internships), (3) gains in personal and educational development, and (4) perceptions of the college environment, including overall satisfaction with college and quality of academic advising. 
The survey relies on student self-reports. A fair amount of research (Baird, 1976; Berdie, 1971; Pace, 1985; Pike, 1995; Pohlmann, 1974) has shown that self-reports are likely to be valid if (1) the information requested is known to the respondents, (2) the questions are phrased clearly and unambiguously, (3) the questions refer to recent activities, (4) the respondents think the questions merit a serious and thoughtful response, and (5) answering the questions does not threaten, embarrass, or violate the privacy of the respondent or encourage the respondent to respond in socially desirable ways (Kuh et al., 2001). The NSSE survey was designed to satisfy all of these conditions.

To answer the guiding research questions we draw on two overlapping samples of students. The first sample was composed of 98,744 undergraduates (49,706 first-year students, 49,038 seniors) from 349 four-year colleges and universities who responded to the NSSE survey in spring 2002. The second sample is a subset of the larger sample and is composed of 17,640 (9,598 first year students, 8,042 seniors) undergraduate students enrolled at 68 Baccalaureate Colleges - Liberal Arts ${ }^{1}$, as defined in the Carnegie classification scheme (McCormick, 2001).

\section{Data Analysis}

The dependent variables were measures of student engagement, perceptions of the campus environment including satisfaction, and selected self-reported outcomes of college (Appendix A). Student engagement was measured using four scales: (1) level of academic challenge, (2) classroom activities that represent higher order thinking (a subset of items that contribute to the academic challenge measure), (3) active and collaborative learning, and (4) diversity-related activities. The supportive campus environment measures included four measures: a supportive campus environment scale, two subscales (interpersonal support and 
support for learning) of supportive campus environment, and an overall satisfaction with college scale. Students' gains in learning and intellectual development were represented by two scales: gains in general education and gains in personal and social development. In addition, three individual measures were used to represent gains in social awareness: gains in understanding self, gains in desire to contribute to community, and gains in understanding others. The items that make up the gains scales are student self reports about the extent to which their college experience has contributed to their growth in these areas.

The data were analyzed in three stages using hierarchical linear modeling (HLM). Because of the nested nature of the data and the intent to estimate institutional effects (Raudenbush \& Bryk, 2002), we used hierarchical linear modeling (HLM). When conducting research on organizational effects, researchers are faced with a decision about unit of analysis. Should they build regression models by aggregating to the institution level, or should they attach institution-level characteristics to individuals? If researchers build models at the institution level, they are prone to "ecologically fallacy”, whereby individual differences mask are masked (King, 1999; Kreft \& deLeeuw, 1998). For example, an analysis based on colleges might reveal that students at smaller colleges are more engaged in effective educational practices than students at large colleges, while an analysis of small colleges might reveal that many students at large colleges are as engaged or more engaged than small college students.

Research where institution-level characteristics are attached to an individual is flawed as well (Ethington, 1997). First, it violates the general assumption of ordinary least squares regression (OLS): Observations are independent of one another. Second, it assumes that individuals within a group are affected identically by group-level characteristics. Finally, the

\footnotetext{
${ }^{1}$ Carnegie defines Baccalaureate Colleges-Liberal Arts as institutions that are primarily undergraduate colleges with major emphasis on baccalaureate programs. During the period studied, they awarded at least half of their
} 
inclusion of group-level variables into an OLS regression equation leads to mis-estimation of standard errors and the wrong number of degrees of freedom, increasing the likelihood of committing a Type I error (indicating that something is statistically significant when it is not).

Using HLM overcomes the problems associated with unit of analysis by simultaneously modeling both individual and institutional effect. HLM partitions the variance between the institution and the student, resulting more accurate parameter estimates. This makes it possible to determine what is an individual-level effect or a group-level effect. Because these effects can be partitioned, each can be modeled with their respective characteristics.

First, we used HLM to explore the impact of differences in student engagement in diversity-related activities by institutional type. In HLM, we are able to allow the intercept to vary, thereby partitioning the variance between the institution and the student. We then are able to model the average institution differences using institutional characteristics. At the institution level, we created dummy coded variables for the five collapsed Carnegie institutional categories for four-year colleges and universities: Doctoral/Research-Extensive, Doctoral/ResearchIntensive, Master’s I \& II, Baccalaureate Colleges - Liberal Arts, and Baccalaureate Colleges General (McCormick, 2001). ${ }^{2}$ To determine whether diversity experiences of students at Liberal Arts Colleges differed from their counterparts at other types of institutions, Liberal Arts Colleges designated as the omitted group. To control for possible confounding variables we included several student-level variables in all of our models. Separate models were run for first-year students and seniors. Table 1 presents the descriptive statistics for the independent variables included in the models.

Insert Table 1 about here

baccalaureate degrees in liberal arts fields. 
In the second stage, we used hierarchical linear modeling to examine the institutional factors that are related to diversity and the effects of diversity experiences on student engagement at Liberal Arts Colleges. Again, we allowed the intercept to vary allowing us to determine the variance that can be attributed to individual student differences. In addition to student-level controls we included several institution-level controls such as sector (public, private), urbanicity (urban, suburban, small town/rural) size (total undergraduate headcount), and a measure of selectivity (derived from the 2002 Barron's College Guide). We modeled separately three institutional measures of different aspects of diversity. First, we tested the influence of structural diversity using a variable that represents the probability that a student will interact with a student from another race (Meyer \& McIntosh, 1992). ${ }^{3}$ We call this the "diversity density index.” We selected this measure because it most accurately represents the amount of diversity on a given campus. As Chang (1999) notes, many studies make the assumption that more students of color equals a more diverse student body and use the proportion of non-White students as their measure of structural diversity. However, this is measure is flawed because it does not take into account the heterogeneity of some college campuses. For example, a Historically Black College or University (HBCU) would be considered highly diverse given that nearly all of the students on campus are non-White. If our fundamental rationale for the benefits accrued by diversity is that students learn from those who are different from them, students at His may be less likely to reap such benefits. Our “diversity density” measure overcomes this heterogeneity problem by including all five racial/ethnic groups in an equation. If the

\footnotetext{
${ }^{2}$ Because of institution type is highly correlated with other institutional characteristics examined in this study (size, urbanicity, sector, and selectivity), no other controls were included at level 2.

${ }^{3}$ Diversity density index: Probability of interacting with a student of a different race was calculated using percentages of different races on a campus : 1-(\%White ${ }^{2}+\%$ African American ${ }^{2}+\%$ Native American $^{2}+\%$ Latino/a $^{2}$ + \%Asian Pacific American ${ }^{2}$ ). Source of race/ethnicity percentages was Integrated Postsecondary Data System (IPEDS) 1998/99 enrollment data.
} 
percentages of the five racial/ethnic groups on a given campus is nearly equal (e.g., 20\%, 20\%, $20 \%, 25 \%, 15 \%)$, then it is more likely that a student will interact with someone from a different race than on a campus where the percentages of the five groups is varies greatly (e.g., $75 \%$, $5 \%$, $10 \%, 10 \%, 0 \%)$

Second, we tested the effects of “climate for diversity,” or students’ perceptions (institutional average) of the emphasis their institution places on encouraging contact among students from different economic, social, and racial or ethnic backgrounds. Third, we tested the influence of “diversity in coursework," the extent to which students reported their classes included readings or discussions related to diversity. Finally, we modeled a construct which we call “diversity press,” by creating a scale made up of the three other diversity measures (seniors $\alpha=.71 ; 1^{\text {st }}$ year students $\alpha=.66$ ). Diversity press represents the institution's commitment to and emphasis on diversity as manifested by the proportional presence of students from different backgrounds attending the institution (structural diversity), the extent to which students perceive that diversity is valued and important, and the degree to which diversity is featured in the curriculum.

In the third and final stage of the analysis, we built a series of hierarchical linear models to explore the relationships between students' engagement with diversity-related activities at liberal arts colleges and measures of student engagement in educationally purposeful activities and their self reported gains in personal and educational growth. We also examine the impact of diversity-related activities on perceptions of student environment and satisfaction.

We calculated effect sizes to assess the magnitude of differences between students’ experiences with diversity at liberal arts colleges and the types of institutions to help interpret the results of the regression equations (Rosenthal \& Rosnow, 1991). The effect size is the proportion 
of a standard deviation change in the dependent variable as a result of a one-unit change in an independent variable. We standardized all of the continuous independent and dependent measures in the models, so the unstandardized coefficients represent effect sizes. The larger the effect size the more likely the differences between groups represent performance that warrants serious discussion and, perhaps, intervention. Taking the advice of Rosenthal and Rosnow (1991) we considered an effect size of .10 or less to reflect a trivial difference, between .10 and .30 small, between .30 and .50 moderate, and greater than .50 large.

\section{Results}

Table 2 presents the coefficients for first-year students and seniors from the multilevel models comparing liberal arts colleges to other types of institutions on average engagement in diversity-related experiences and self-reported gains in understanding people from diverse backgrounds. Both first-year and senior students at liberal arts colleges, on average, are more likely than their peers at other types of colleges and universities to engage in diversity-related activities (effect sizes ranging from .19 to .30). While the effects are somewhat smaller (.10 to .23), students at liberal arts colleges reported statistically significantly higher gains in understanding diversity than did students at other types of colleges.

Insert Table 2 about here

\section{$\underline{\text { Institutional Context }}$}

The high levels of student engagement in diversity-related activities and self-reported gains in understanding people from different backgrounds at liberal arts colleges suggest that many of these colleges offer a distinctive educational experience for students compared with other types of schools. The next set of models is run only on students from liberal arts colleges 
and attempts to explain why these institutions perform so well compared with others by exploring the influence of their institutional features on diversity-related experiences.

Table 3 presents the coefficients for the four institutional diversity measures. The diversity density index, or the probability that a student will interact with a student of another race, significantly predicts student engagement and gains in only a few areas. As expected, firstyear and senior students at institutions with high diversity density scores are more likely to engage in diversity-related activities and report gains in understanding people from other backgrounds and cultures. Diversity density also is positively related to gains in personal and social development for seniors, but negatively related to satisfaction and interpersonal support.

Insert Table 3 about here

The institutional climate for diversity, or encouragement to interact with people from different backgrounds, is positively related to almost all of the engagement and gains measures. As expected, the strongest effects for both first-year and senior students can be seen in the average engagement in diversity-related activities and gains in understanding diversity. However, the degree to which an institution encourages interactions with diverse peers is not significantly related to level of academic challenge for either seniors or first-year students.

Diversity in coursework, or the frequency with which students encounter diverse perspectives in class, is also positively related to many of the dependent measures. However, for both first-year and senior students overall satisfaction with college and the supportive campus environment measure were unrelated to emphasizing diverse perspectives in the classroom.

Given these findings, it is no surprise that the diversity press construct is positively related to many of our dependent measures. As with the results from the other models in Table 3, diversity press is most strongly related to engagement in diversity-related activities and gains in 
understanding diversity for both first-year students and seniors. For first-year students, diversity press was positively related to all the dependent measures except academic challenge, satisfaction and supportive campus environment. For seniors, the only measures that were not related to diversity press were satisfaction, supportive campus environment, and gains in understanding others.

\section{$\underline{\text { Diversity and Engagement at Liberal Arts Colleges }}$}

Table 4 displays the effect sizes for engaging in diversity-related activities after controlling for institutional and individual characteristics for students at liberal arts colleges. Student experiences with diversity at liberal arts colleges are positively related to all the dependent measures. Students who participate in diversity-related activities report higher levels of academic challenge, participate more frequently in active and collaborative learning, report greater gains in personal and educational growth, and are more satisfied with their college experience. They also perceive that their campus environment more strongly supports their academic and social needs. The effect sizes range from .27 to .44 , with the largest effects related to academic challenge, active and collaborative learning, and personal and social development gains.

Insert Table 4 about here

\section{$\underline{\text { Limitations }}$}

Because this study focuses primarily on institutional effects, we used hierarchical linear modeling. However, the between-school variance is quite small for many of the dependent measures. The intra-class correlations (ICC), or the proportion of variance explained by institution membership, ranged from .04 to .11. Some might argue that it is unnecessary to use multilevel models with such small ICCs. At the same time, there two compelling reasons why 
the HLM approach is preferred over ordinary least squares (OLS) regression for this study. First, all of the model reliabilities are quite high (none are below .6), which suggests that using multilevel modeling to estimate the intercepts is appropriate (Kreft \& Leeuw, 1998). Second, if we attempt to model group-level effects with OLS by attaching institutional characteristics to individuals, we will not accurately capture the effect of these characteristics and will misestimate their standard errors (Ethington, 1997).

Another limitation is related to the validity of self-reported gains. As Pascarella (2001) and others point out, gain scores may be confounded by students' entering characteristics. However, Pike (1999) provides some evidence to suggest that gain scores are not significantly related to entering ability. Although the concerns about self-reported data are legitimate, the gains measures are only one of several sets of dependent variables used in this study. In addition, because of ceiling effects we might expect the self-reported gains of students at liberal arts colleges, many of which employ more selective admissions standards, to be smaller overall than students at master's granting and baccalaureate general colleges. That is, students at the latter types of schools may start college at lower levels of intellectual and personal development and have more room to move upward on the self-report gains measures. Inasmuch as the pattern of results overwhelmingly favor liberal arts colleges, the concerns about the validity of selfreported gains should be interpreted in the context of the complete set of findings.

Our results should also be considered in light of possible inadequacies in the 2000 Carnegie Classification scheme. Some might argue that the system is so diverse even within categories in the characteristics of institutions that the categories themselves have little meaning. While we recognize such limitations, the Carnegie Classification is the most recent and best know way to categorize colleges and universities. 
Additionally, some of the effect sizes are relatively small. In particular, some of the effects of the institutional diversity measures for liberal arts colleges are trivial. Even so, the pattern of the effect sizes and the magnitude of other effect sizes favoring liberal arts colleges cannot be overlooked.

Finally, given that the data used in this study are cross-sectional, we are unable to control for self selection. Perhaps students who matriculate to liberal arts colleges are more predisposed to seek out people from different backgrounds or believe that these colleges provide them with opportunities for these types of interactions. While the latter is not likely, given the limited structural diversity of many liberal arts colleges, the former is possible and warrants a cautionary note.

\section{Discussion}

The findings from this study suggest that liberal arts colleges create distinctive learning environments for students in terms of diversity experiences. The advantage is consistent across the outcomes measures used in this study and often supported by substantial effect sizes even after controlling for student and other institutional features. Students at liberal arts colleges are significantly more likely than their counterparts at other types of institutions to engage in diversity-related activities and to report greater gains in understanding people from diverse backgrounds.

In terms of the overall effects of diversity experiences across different types of colleges and universities, the results generally corroborate the research showing positive relationships between diversity and desirable outcomes of college. That is, students who engaged in diversityrelated activities more frequently reported higher levels of academic challenge, greater opportunities for active and collaborative learning, and a more supportive campus environment. 
They were also more satisfied with their college experience and reported greater gains since starting college in a variety of areas.

Liberal arts colleges generally perform well on measures of student engagement compared to other types of colleges and universities (Astin, 1993, 1999; Hu \& Kuh, 2003; Kuh, 2003; Kuh \& Hu, 2001; National Survey of Student Engagement, 2000, 2001, 2002). But the pattern of results favoring liberal arts colleges in terms of diversity experiences is surprising if for no other reason that many of these institutions are not naturally imbued with some forms of diversity. For example, many liberal arts colleges are located for historical reasons in rural settings (Rudolph, 1990), which are not racially or socioeconomically diverse or viewed as desirable collegiate environments by many students from historically underrepresented groups (e.g, students of color, first-generation college students). As a result, liberal arts colleges should not be expected to score well on the diversity density index. Figure 1 displays the relatively low structural diversity at Liberal Arts Colleges. Although we see differences between and within institution types, only Baccalaureate General Institutions had a lower median diversity density index than Liberal Arts Colleges.

Insert Figure 1 about here

Consistent with some previous research, first-year students’ diversity density was negatively related to satisfaction and perceived interpersonal support (Hu \& Kuh, 2003; Rothman, Lipset, \& Nevitte, 2003). However, the diversity press model does not show these negative effects, indicating that the negative impact of diversity density on satisfaction and interpersonal supported is ameliorated when institutions offer courses that emphasize diverse perspectives and create a climate that promotes interactions between people from different backgrounds. This finding is consistent with Hurtado et al. (1999) and Chang (1999) who argue 
that structural diversity in and of itself does not necessarily result in an environment supportive of diversity. In order for institutions to optimize the benefits of structural diversity they need to display a commitment to diversity and provide opportunities for diverse interactions (Chang, 1999, p. 392). Our findings support these claims and suggest that one way to do this is to present diverse perspectives in the classroom. Additionally, institutions need to find other ways to communicate the value of diversity and support the academic and social needs of students from different backgrounds. In the context of liberal arts colleges, most of which tend to be relatively small, apparently the magnitude of the number of students from different backgrounds does not matter as much to deriving the benefits of diversity experiences as does the quality of interactions across differences that the campus environment encourages and nurtures. $\underline{\text { Implications }}$

Taken together, the findings from this study indicate that an institution does not have to be highly structurally diverse to foster meaningful diversity experiences. Few of the Liberal Arts Colleges in this study were as or more structurally diverse than, for example, larger researchintensive universities. Yet, Liberal Arts Colleges appeared to have created environments that took advantage of the limited diversity on campus. Institutions that use the absence of structural diversity as an explanation for why they are unable to enhance student learning through diversity-related activities could look to Liberal Arts Colleges for ideas as to how they are able to promote diversity experiences.

Liberal Arts Colleges are not the only type of institutions that have effectively infused diversity experiences into the undergraduate program. In fact, much can be learned from large universities about their innovative approaches that facilitate cross-group interactions, such as the 
University of Michigan, University of Maryland, Indiana University, and Arizona State

University. These institutions have implemented intergroup dialogues that bring together diverse groups of students with the purpose of discussing issues related to their diversity. So far, the research on the impact of these experiences is promising, suggesting that these dialogues are an effective way for students to learn to become citizens in an increasingly diverse society (Schoem \& Hurtado, 2001).

The field would benefit from additional efforts to codify programs, policies, and practices both at liberal arts colleges which as a group seem to be relatively effective at promoting beneficial experiences with diversity as well as other types of institutions that perform better than predicted in this area (Garcia et al., 2002). In addition, a diversity audit tool similar to the one described by Green (1989) that reliably assesses the factors and conditions that encourage students to experience diversity could be profitably used by institutions and to external groups such as accreditation organizations.

\section{Conclusion}

This study adds to our understanding of institutional characteristics that are related to students' experiences with diversity. As colleges and universities prepare students to live and work in an increasingly diverse democracy, many liberal arts colleges appear to have created learning environments distinguished by an accentuated diversity press. Opportunities to interact across racial, religious, and socio-economic lines seem to be the critical factor in terms of creating an environment that supports experiences with diversity and for cultivating the skills and dispositions that are considered essential to be effective in an increasingly multicultural society. Although structural diversity is not a sufficient condition for realizing the benefits that accrue from experiencing diversity, recruiting students from a broad range of backgrounds, 
including race and ethnicity, remains important. Indeed, without a minimal level of structural diversity it would be very difficult to have the ingredients in place to promote the cross-cultural interactions that are essential for deep learning about diversity. 


\section{CONSTRUCTS AND VARIABLES}

\section{Student Engagement}

Level of Academic Challenge (seniors $\alpha=.76 ; 1^{\text {st }}$ year students $\alpha=.73$ )

- Hours per week preparing for class (studying, reading, writing, rehearsing, and other activities related to your academic program)

- Worked harder than you thought you could to meet an instructor's standards or expectations

- Number of assigned textbooks, books, or book-length packs of course readings during the current school year

- Number of written papers or reports of 20 pages or more during the current school year

- Number of written papers or reports between 5 and 19 pages during the current school year

- Number of written papers or reports of fewer than 5 pages during the current school year

- Coursework emphasizes: Analyzing the basic elements of an idea, experience, or theory

- Coursework emphasizes: Synthesizing and organizing ideas, information, or experiences into new, more complex interpretations and relationships

- Coursework emphasizes: Making judgments about the value of information, arguments, or methods

- Coursework emphasizes: Applying theories or concepts to practical problems or in new situations

- Campus environments emphasize: Spending significant amounts of time studying and on academic work

Higher-order thinking activities (seniors $\alpha=.81 ; 1^{\text {st }}$ year students $\alpha=.79$ )

- Coursework emphasizes: Analyzing the basic elements of an idea, experience, or theory

- Coursework emphasizes: Synthesizing and organizing ideas, information, or experiences into new, more complex interpretations and relationships

- Coursework emphasizes: Making judgments about the value of information, arguments, or methods

- Coursework emphasizes: Applying theories or concepts to practical problems or in new situations

Active and Collaborative Learning (seniors $\alpha=.63 ; 1^{\text {st }}$ year students $\alpha=.61$ )

- Asked questions in class or contributed to class discussions

- Made a class presentation

- Worked with other students on projects during class

- Worked with classmates outside of class to prepare class assignments

- Tutored or taught other students (paid or voluntary)

- Participated in a community-based project as part of a regular course

- Discussed ideas from your readings or classes with others outside of class (students, family members, coworkers, etc.)

Diversity-related Activities (seniors $\alpha=.68 ; 1^{\text {st }}$ year students $\alpha=.67$ )

- Had serious conversations with students of a different race or ethnicity than your own

- Had serious conversations with students who differ from you in terms of their religious beliefs, political opinions, or personal values

- Campus Environments Emphasize: Encouraging contact among students from different economic, social, and racial or ethnic backgrounds

- Included diverse perspectives (different races, religions, genders, political beliefs) in class discussions or assignments

\section{QUESTION RESPONSE SETS}

0, 1-5, 6-10, 11-15, 16-20, 21-25, 26-30, More than 30

Very often, often, sometimes, never

None, 1-4, 5-10, 11-20, more than 20

None, 1-4, 5-10, 11-20, more than 20

None, 1-4, 5-10, 11-20, more than 20

None, 1-4, 5-10, 11-20, more than 20

Very much, quite a bit, some, very little

Very much, quite a bit, some, very little

Very much, quite a bit, some, very little

Very much, quite a bit, some, very little

Very much, quite a bit, some, very little

Very much, quite a bit, some, very little

Very much, quite a bit, some, very little

Very much, quite a bit, some, very little

Very much, quite a bit, some, very little

Very often, often, sometimes, never Very often, often, sometimes, never Very often, often, sometimes, never Very often, often, sometimes, never Very often, often, sometimes, never Very often, often, sometimes, never Very often, often, sometimes, never

Very often, often, sometimes, never

Very often, often, sometimes, never

Very much, quite a bit, some, very little

Very often, often, sometimes, never 


\section{CONSTRUCTS AND VARIABLES}

\section{Supportive Campus Environment}

Supportive Campus Environment (seniors $\alpha=.79$; $1^{\text {st }}$ year students $\alpha=.79$ )

- Campus Environments Emphasize: Providing the support you need to help you succeed academically

- Campus Environments Emphasize: Helping you cope with your non-academic responsibilities (work, family, etc.)

- Campus Environments Emphasize: Providing the support you need to thrive socially

- Quality: Relationships with other students

- Quality: Relationships with faculty members

- Quality: Relationships with administrative personnel and offices Interpersonal Support (seniors $\alpha=.63 ; 1^{\text {st }}$ year students $\alpha=.66$ )

- Quality: Relationships with other students

- Quality: Relationships with faculty members

- Quality: Relationships with administrative personnel and offices Support for Learning (seniors $\alpha=.77 ; 1^{\text {st }}$ year students $\alpha=.77$ )

- Campus Environments Emphasize: Providing the support you need to help you succeed academically

- Campus Environments Emphasize: Helping you cope with your non-academic responsibilities (work, family, etc.)

- Campus Environments Emphasize: Providing the support you need to thrive socially

Satisfaction (seniors $\alpha=.80 ; 1^{\text {st }}$ year students $\alpha=.78$ )

- How would you evaluate your entire educational experience at this institution?

- If you could start over again, would you go to the same institution you are now attending?

\section{Gains in Learning and Intellectual Development}

Gains in Personal and Social Development (seniors $\alpha=.81 ; 1^{\text {st }}$ year students $\alpha=.80)$

- Contributed to: Developing a personal code of values and ethics

- Contributed to: Understanding people of other racial and ethnic backgrounds

- Contributed to: Understanding yourself

- Contributed to: Improving the welfare of your community

- Contributed to: Learning effectively on your own

- Contributed to: Working effectively with others

Gains in General Education (seniors $\alpha=.81 ; 1^{\text {st }}$ year students $\alpha=.79$ )

- Contributed to: Writing clearly and effectively

- Contributed to: Speaking clearly and effectively

- Contributed to: Thinking critically and analytically

- Contributed to: Acquiring broad general education

\section{QUESTION RESPONSE SETS}

Very much, quite a bit, some, very little

Very much, quite a bit, some, very little

Very much, quite a bit, some, very little

$1=$ Unfriendly, unsupportive, sense of alienation; 7=friendly, supportive, sense of belonging 1=Unavailable, unhelpful, unsympathetic; 7=Available, helpful, sympathetic

$1=$ Unhelpful, inconsiderate, rigid

1=Helpful, considerate, flexible;

1=Unfriendly, unsupportive, sense of alienation; 7=friendly, supportive, sense of belonging

1=Unavailable, unhelpful, unsympathetic; 7=Available, helpful, sympathetic

$1=$ Unhelpful, inconsiderate, rigid

1=Helpful, considerate, flexible;

Very much, quite a bit, some, very little

Very much, quite a bit, some, very little

Very much, quite a bit, some, very little

Excellent, good, fair, poor

Excellent, good, fair, poor

Very much, quite a bit, some, very little Very much, quite a bit, some, very little Very much, quite a bit, some, very little Very much, quite a bit, some, very little Very much, quite a bit, some, very little Very much, quite a bit, some, very little

Very much, quite a bit, some, very little Very much, quite a bit, some, very little Very much, quite a bit, some, very little Very much, quite a bit, some, very little 


\section{CONSTRUCTS AND VARIABLES}

Gains in Practical Competence (seniors $\alpha=.76 ; 1^{\text {st }}$ year students $\alpha=.76$ )

- Contributed to: Acquiring job or work-related knowledge and skills

- Contributed to: Using computing and information technology

- Contributed to: Analyzing quantitative problems

- Contributed to: Solving complex real-world problems

Gains in Social Awareness

Gains in understanding diversity

- Contributed to: Understanding diversity

Gains in contributing to community

- Contributed to: Improving the welfare of your community

Gains in understanding self

- Contributed to: Understanding yourself

Gains in understanding others

- Contributed to: Understanding others

Diversity press (seniors $\alpha=.71 ; 1^{\text {st }}$ year students $\alpha=.66$ )

- Diversity density index

- Diversity in coursework -- institutional average of included diverse perspectives (different races, religions, genders, political beliefs) in class discussions or assignments

- Climate for diversity -- institutional average of college emphasizes encouraging contact among students from different economic, social, and racial or ethnic backgrounds

\section{QUESTION RESPONSE SETS}

Very much, quite a bit, some, very little Very much, quite a bit, some, very little Very much, quite a bit, some, very little Very much, quite a bit, some, very little

Very much, quite a bit, some, very little

Very much, quite a bit, some, very little

Very much, quite a bit, some, very little

Very much, quite a bit, some, very little 


\section{References}

Alger, J. R. (1997). The educational value of diversity. Academe, 83(1), 20-23.

Astin, A. W. (1993). What matters in college: Four critical years revisited. San Francisco, CA: Jossey-Bass.

Astin, A. W. (1999). How the liberal arts college affects students. Daedulus, 128(1), 77-100.

Astone, B., \& Nunez-Wormack, E. (1990). Pursuing diversity: Recruiting college minority students. Washington, D.C.: George Washington University.

Baird, L. L. (1976). Biographical and educational correlates of graduate and professional school admissions test scores. Educational and Psychological Measurement, 36(2), 415-420.

Berdie, R. F. (1971). Self-claimed and tested knowledge. Educational and Psychological Measurement, 31(3), 629-636.

Bowen, W. G., \& Bok, D. (1998). The shape of the river: Long-term consequences of considering race in college and university admissions. Princeton, N.J.: Princeton University Press.

Chang, M. J. (1999). Does racial diversity matter? The educational impact of a racially diverse undergraduate population. Journal of College Student Development, 40(4), 377-395.

Chang, M. J. (2001). The positive educational effects of racial diversity on campus. In G. Orfield \& M. Kurlaender (Eds.), Diversity challenged: Evidence on the impact of affirmative action (pp. 175-186). Cambridge, MA: The Civil Rights Project, Harvard University.

Chang, M. J. (2002). Racial dynamics on campus: What student organizations can tell us. About Campus, 7(1), 2-8.

Chickering, A.W., \& Gamson, Z.F. (1987). Seven principles for good practice in undergraduate education. AAHE Bulletin, 39(7), 3-7. 
Clark, B. R. (1970). The distinctive college: Antioch, Reed \& Swarthmore. Chicago: Aldine Pub. Co.

Coser, R. (1975). The complexity of roles as a seedbed of individual autonomy. In L. A. Coser (Ed.), The idea of social structure: Papers in honor of Robert K. Merton (pp. 105-127). New York: Harcourt Brace Jovanovich.

Duster, T. (1993). The diversity of California at Berkeley: An emerging reformulation of "competence" in a multicultural world. In B. W. Thompson \& S. Tyagi (Eds.), Beyond a dream deferred: Multicultural education and the politics of excellence (pp. 143-157). Minneapolis, MN: University of Minnesota Press.

Ethington, C. A. (1997). A hierarchical linear modeling approach to studying college effects. In J. Smart (Ed.), Higher education handbook of theory and research, Vol. 12 (pp. 165-194). Edison, NJ: Agathon.

Garcia, M., Hudgins, C., Musil, C. M., Nettles, M. T., Sedlacek, W. E., \& Smith, D. G. (2002). Assessing campus diversity initiatives: A guide for campus practitioners. Washington, DC: American Association of Colleges \& Universities.

Green, M. F. (1989). Minorities on campus --A handbook for enhancing diversity. Washington, D.C: American Council on Education.

Gurin, P. (1999). Expert report of Patricia Gurin. In Mich. (Ed.), The compelling need for diversity in higher education, Gratz et al. v. Bollinger et al, No. 97-75237 and Grutter et al. v. Bollinger et al. No. 97-75928. Ann Arbor, MI: The University of Michigan. 
Hu, S., \& Kuh, G. D. (2002). Being (dis)engaged in educationally purposeful activities: the influences of student and institutional characteristics. Research in Higher Education, $\underline{43}(5), 555-575$.

Hu, S., \& Kuh, G.D. (2003). Diversity experiences and college student learning and personal development. Journal of College Student Development, 44(3), 320-334.

Hurtado, S., Milem, J., Clayton-Pedersen, A., \& Allen, W. (1998). Enacting campus climates for racial/ethnic diversity through educational policy and practice. The Review of Higher Education, 21(3). 278-297.

Hurtado, S., Milem, J., Clayton-Pedersen, A., \& Allen, W. (1999). Enacting diverse learning environments: Improving the climate for racial/ethnic diversity in higher education. Washington, D.C.: The George Washington University.

Kreft, I. G. G., \& de Leeuw, J. (1998). Introducing multilevel modeling. London: Thousand Oaks, Calif.: Sage.

Kuh, G. D. (2001). Assessing what really matters to student learning: inside the national survey of student engagement. Change, 33(3), 10-17, 66.

Kuh, G. D. (2003). What we're learning about student engagement from NSSE. Change, 35(2), 35-44.

Kuh, G. D., \& Hu, S. (2001). Learning productivity at research universities. Journal of Higher Education, 72(1), 1-28.

Kuh, G. D., Schuh, J. H., Whitt, E. J., \& Associates. (1991). Involving colleges: Successful approaches to fostering student learning and development outside the classroom. San Francisco, CA: Jossey-Bass. 
McCormick, A. C. (2001). The Carnegie classification of institutions of higher education, 2000 Edition. Menlo Park, CA: The Carnegie Foundation for the Advancement of Teaching. Meyer, P., \& McIntosh, S. (1992). The USA Today index of ethnic diversity. International Journal of Public Opinion Research, Spring, 56.

Milem, J. F. (1994). College, students, and racial understanding. Thought \& Action, 9(2), 51-92.

Milem, J. F., \& Hakuta, K. (2000). The benefits of racial and ethnic diversity in higher education. In D. Wilds (Ed.), Minorities in higher education: Seventeenth annual status report (pp. 39-67). Washington, D. C.: American Council on Education.

National Survey of Student Engagement (2000). The NSSE 2000 report: National benchmarks of effective educational practice. Bloomington, IN: Indiana University Bloomington.

National Survey of Student Engagement (2001). Improving the college experience: National benchmarks of effective educational practice. Bloomington, IN: Indiana University Bloomington.

National Survey of Student Engagement (2002). From promise to progress: How colleges and universities are using engagement results to improve collegiate quality. Bloomington, IN: Indiana University Bloomington.

Pace, C. R. (1985). The credibility of student self-reports. Los Angeles: Center for the Study of Evaluation, University of California Los Angeles.

Pascarella, E. T. (2001). Using student self-reported gains to estimate college impact: A cautionary tale. Journal of College Student Development, 42(5), 488-492.

Pascarella, E. T., Edison, M., Nora, A., Hagedorn, L. S., \& Terenzini, P. T. (1996). Influences on students openness to diversity and challenge in the first year of college. Journal of Higher Education, 67(2), 174-195. 
Pike, G. R. (1995). The relationship between self reports of college experiences and achievement test scores. Research in Higher Education, 36(1) 1-21.

Pike, G. R. (1999). The constant error of the halo in educational outcomes research. Research in Higher Education, 40(1), 61-86.

Pohlmann, J. T. (1974). A description of effective college teaching in five disciplines as measured by student ratings. Research in Higher Education, 4(4), 335-346.

Rosenthal, R., \& Rosnow, R. L. (1991). Essentials of behavioral research: methods and data analysis (2nd ed.). New York: McGraw-Hill.

Rothman, S., Lipset, S. M., \& Nevitte, N. (2003). Does enrollment diversity improve university education? International Journal of Public Opinion Research, 15(1), 8-26.

Rudenstine, N. (1996). Why a diverse student body is so important. Chronicle of Higher Education, 42, B1-B2.

Rudolph, F. (1990). The American college and university: A history. Athens, GA: University of Georgia Press.

Schoem, D. L., \& Hurtado, S. (Eds.). (2001). Intergroup dialogue: Deliberative democracy in school, college, community, and workplace. Ann Arbor, MI: University of Michigan Press.

Shulman, L. S. (2002). Making differences: A table of learning. Change, 34(6), 36-45.

Sleeter, C. E., \& Grant, C. A. (1994). Making choices for multicultural education: Five approaches to race class and gender. New York: Maxwell Macmillan.

Tierney, W. G. (1993). Building communities of difference: Higher education in the twenty-first century. Westport, CT: Bergin \& Garvey. 
Diversity at Liberal Arts Colleges 30

Townsend, B. K., Newell, L. J., \& Wiese, M. D. (1992). Creating distinctiveness: lessons from uncommon colleges and universities. Washington, DC: George Washington University. 
Table 1. Descriptive statistics of independent variables.

\begin{tabular}{|c|c|c|c|c|c|c|c|c|}
\hline & \multicolumn{4}{|c|}{ First-Year Students } & \multicolumn{4}{|c|}{ Seniors } \\
\hline & \multicolumn{2}{|c|}{ National } & \multicolumn{2}{|c|}{ Liberal Arts } & \multicolumn{2}{|c|}{ National } & \multicolumn{2}{|c|}{ Liberal Arts } \\
\hline & Mean & Std. Dev. & Mean & Std. Dev. & Mean & Std. Dev. & Mean & Std. Dev. \\
\hline \multicolumn{9}{|l|}{ Independent Variables - Level 1} \\
\hline Female ${ }^{*}$ & 0.66 & 0.47 & 0.67 & 0.47 & 0.65 & 0.48 & 0.68 & 0.47 \\
\hline Age & 19.16 & 4.11 & 18.87 & 2.58 & 25.21 & 7.50 & 23.17 & 5.97 \\
\hline First-generation college* & 0.38 & 0.49 & 0.29 & 0.45 & 0.43 & 0.50 & 0.32 & 0.47 \\
\hline African American* & 0.06 & 0.23 & 0.04 & 0.19 & 0.05 & 0.22 & 0.03 & 0.17 \\
\hline Native American* & 0.00 & 0.07 & 0.00 & 0.07 & 0.01 & 0.08 & 0.00 & 0.07 \\
\hline Asian Pacific American* & 0.06 & 0.24 & 0.04 & 0.20 & 0.06 & 0.24 & 0.05 & 0.22 \\
\hline White* & 0.78 & 0.42 & 0.83 & 0.37 & 0.79 & 0.41 & 0.84 & 0.37 \\
\hline Latino/a* & 0.05 & 0.21 & 0.02 & 0.14 & 0.04 & 0.20 & 0.02 & 0.13 \\
\hline Other minority* & 0.01 & 0.08 & 0.01 & 0.08 & 0.01 & 0.08 & 0.01 & 0.09 \\
\hline Major-Humanities* & 0.08 & 0.27 & 0.11 & 0.31 & 0.10 & 0.31 & 0.17 & 0.37 \\
\hline Major-Math \& Science* & 0.15 & 0.36 & 0.14 & 0.34 & 0.18 & 0.39 & 0.17 & 0.37 \\
\hline Major-Professional* & 0.28 & 0.45 & 0.13 & 0.34 & 0.34 & 0.47 & 0.16 & 0.37 \\
\hline Major-Social Sciences* & 0.10 & 0.30 & 0.13 & 0.33 & 0.16 & 0.37 & 0.25 & 0.43 \\
\hline Major-Other* & 0.39 & 0.49 & 0.50 & 0.50 & 0.21 & 0.41 & 0.25 & 0.43 \\
\hline Greek* & 0.11 & 0.32 & 0.16 & 0.37 & 0.14 & 0.34 & 0.22 & 0.42 \\
\hline Grades* & 3.45 & 1.12 & 3.50 & 1.04 & 3.70 & 1.01 & 3.78 & 0.93 \\
\hline Transfer* & 0.07 & 0.25 & 0.04 & 0.19 & 0.39 & 0.49 & 0.19 & 0.40 \\
\hline Full-time* & 0.95 & 0.21 & 0.98 & 0.13 & 0.83 & 0.37 & 0.92 & 0.28 \\
\hline \multicolumn{9}{|l|}{ Independent Variables - Level 2} \\
\hline Doctoral Research-Extensive* & 0.14 & 0.35 & & & 0.14 & 0.35 & & \\
\hline Doctoral Research-Intensive* & 0.09 & 0.29 & & & 0.09 & 0.29 & & \\
\hline Master's I and II* & 0.44 & 0.50 & & & 0.44 & 0.50 & & \\
\hline Baccalaureate-Liberal Arts* & 0.20 & 0.40 & & & 0.20 & 0.40 & & \\
\hline Baccalaureate-General* & 0.14 & 0.34 & & & 0.14 & 0.34 & & \\
\hline Urban* & & & 0.41 & 0.49 & & & 0.41 & 0.50 \\
\hline Suburban* & & & 0.23 & 0.43 & & & 0.22 & 0.42 \\
\hline Town/rural* & & & 0.36 & 0.48 & & & 0.37 & 0.49 \\
\hline Private* & & & 0.86 & 0.35 & & & 0.87 & 0.34 \\
\hline Undergraduate headcount* & & & 1.63 & 0.90 & & & 1.64 & 0.90 \\
\hline Selectivity (Barron's 2002) & & & 4.11 & 1.02 & & & 4.10 & 1.02 \\
\hline Diversity density index & & & 0.29 & 0.16 & & & 0.33 & 0.16 \\
\hline Climate for diversity & & & 2.52 & 0.33 & & & 2.67 & 0.30 \\
\hline Diversity in class & & & 2.95 & 0.24 & & & 2.86 & 0.22 \\
\hline$\underline{D i v e r s i t y ~ p r e s s ~}^{¥}$ & & & 1.00 & 0.00 & & & 1.00 & 0.00 \\
\hline
\end{tabular}

\footnotetext{
*Dummy-coded variable where $1=$ yes and $2=$ no

${ }^{+}$Barron's (2002) selectivity score combines median SAT/ACT score with other measures of an institution's admissions requirements and ranges from 1 to 6

¥ Standardized factor score of diversity density index, climate for diversity, and diversity in class
} 
Table 2. Effect sizes for Diversity-related Variables by Carnegie Classification (Liberal Arts Colleges omitted category)

\begin{tabular}{|c|c|c|c|c|c|c|c|c|c|c|c|c|c|c|c|c|}
\hline \multirow[b]{2}{*}{ Dependent variable } & \multicolumn{3}{|c|}{ DRU-Extensive } & & \multicolumn{3}{|c|}{ DRU-Intensive } & \multicolumn{5}{|c|}{ MA I \& II } & \multicolumn{4}{|c|}{ BACGEN } \\
\hline & $\begin{array}{c}1 \text { st } \\
\text { year }\end{array}$ & & Seniors & & $\begin{array}{c}1 \text { st } \\
\text { year }\end{array}$ & & Seniors & & $\begin{array}{c}1 \text { st } \\
\text { year }\end{array}$ & & Seniors & & $\begin{array}{c}1 \text { st } \\
\text { year }\end{array}$ & & Seniors & \\
\hline Diversity-related activities & -0.21 & $* * *$ & -0.19 & $* * *$ & -0.24 & $* * *$ & -0.25 & $* * *$ & -0.27 & $* * *$ & -0.19 & $* * *$ & -0.30 & $* * *$ & -0.28 & $* * *$ \\
\hline $\begin{array}{l}\text { Gains - Understanding } \\
\text { diversity }\end{array}$ & -0.11 & * & -0.14 & $* *$ & -0.14 & $*$ & -0.11 & $*$ & -0.18 & $* * *$ & -0.10 & * & -.23 & $* * *$ & -0.12 & $* *$ \\
\hline
\end{tabular}

${ }^{*} \mathrm{p}<.05, * * \mathrm{p}<.01, * * * \mathrm{p}<.001$

Level 1 controls - age, race, gender, transfer, grades, Greek, major, full-time, first generation college 
Diversity at Liberal Arts Colleges 33

Table 3. Effect sizes for statistically significant $(\mathrm{p}<.05)$ predictors of engagement and gains for students at Liberal Arts Colleges

\begin{tabular}{|c|c|c|c|c|c|c|c|c|}
\hline \multirow[b]{4}{*}{ Dependent variable } & \multicolumn{4}{|c|}{ First-year students } & \multicolumn{4}{|c|}{ Seniors } \\
\hline & \multirow{2}{*}{$\begin{array}{l}\text { Diversity } \\
\text { Density }\end{array}$} & \multirow{2}{*}{$\begin{array}{c}\text { Climate } \\
\text { For }\end{array}$} & \multirow{2}{*}{$\begin{array}{c}\text { Diversity } \\
\text { In }\end{array}$} & \multirow{3}{*}{$\begin{array}{c}\text { Diversity } \\
\text { Press }^{e}\end{array}$} & \multirow{3}{*}{$\begin{array}{l}\text { Diversity } \\
\text { Density } \\
\text { Index }^{\mathrm{b}}\end{array}$} & \multirow{3}{*}{$\begin{array}{l}\text { Climate } \\
\text { For } \\
\text { Diversity }^{\mathrm{c}}\end{array}$} & \multirow{3}{*}{$\begin{array}{c}\text { Diversity } \\
\text { In } \\
\text { Coursework }\end{array}$} & \multirow{3}{*}{$\begin{array}{l}\text { Diversity } \\
\text { Press }^{e}\end{array}$} \\
\hline & & & & & & & & \\
\hline & Index ${ }^{\mathrm{b}}$ & Diversity $^{\mathrm{c}}$ & Coursework $^{\mathrm{d}}$ & & & & & \\
\hline \multicolumn{9}{|l|}{ Student Engagement } \\
\hline Academic challenge & & & 0.09 & & & & 0.09 & 0.06 \\
\hline Higher order thinking & & 0.06 & 0.11 & 0.08 & & 0.06 & 0.09 & 0.07 \\
\hline Active and Collaborative & & 0.11 & 0.13 & 0.11 & & 0.08 & 0.11 & 0.09 \\
\hline Diversity-related activities & 0.17 & 0.23 & 0.26 & 0.27 & 0.19 & 0.27 & 0.27 & 0.21 \\
\hline \multicolumn{9}{|l|}{ Supportive Campus Environment } \\
\hline Supportive Campus Environment & & 0.07 & & & & 0.08 & & \\
\hline Interpersonal & -0.06 & 0.05 & & & & & & \\
\hline Support for learning & & 0.09 & 0.05 & 0.06 & & 0.09 & 0.07 & 0.06 \\
\hline Satisfaction & -0.06 & 0.06 & & & & 0.06 & & \\
\hline \multicolumn{9}{|c|}{ Gains in Learning and Intellectual Development } \\
\hline Gains - Personal/social & & 0.12 & 0.11 & 0.11 & 0.05 & 0.13 & 0.12 & 0.12 \\
\hline \multicolumn{9}{|l|}{ Gains - general education } \\
\hline \multicolumn{9}{|l|}{ Gains in Social Awareness } \\
\hline Gains- Understanding diversity & 0.12 & 0.21 & 0.20 & 0.22 & 0.15 & 0.25 & 0.23 & 0.25 \\
\hline Gains - Contributing to community & & 0.07 & 0.07 & 0.06 & & 0.10 & 0.10 & 0.10 \\
\hline Gains - Understanding self & & 0.05 & 0.05 & 0.05 & & 0.06 & 0.06 & 0.06 \\
\hline Gains - Understanding others & & 0.09 & 0.06 & 0.06 & & & 0.05 & 0.05 \\
\hline
\end{tabular}

${ }^{\mathrm{a} L e v e l} 2$ controls - urbanicity, sector, size, and selectivity

Level 1 controls - age, race, gender, transfer, grades, Greek, major, full-time, first generation college

${ }^{b}$ Diversity density index (Meyer \& McIntosh, 1992)

1-(White ${ }^{2}+$ Black $^{2}+$ Native American ${ }^{2}+$ Latino $^{2}+$ Asian Pacific American $\left.{ }^{2}\right)$

Institution average of perception that institution encourages diverse interactions

${ }^{\mathrm{d}}$ Institutional average of including diverse perspectives in class

ésum of the diversity density index, climate for diversity, and diversity in coursework scales. 
Table 4. Effect sizes for diversity-related activities for students at Liberal Arts Colleges

\begin{tabular}{lcc}
\hline Dependent variable & $1^{\text {st }}$-year students & Seniors \\
\hline Student Engagement & 0.43 & 0.41 \\
Academic challenge & 0.42 & 0.41 \\
Higher order & 0.44 & 0.43 \\
Active and Collaborative & & \\
Supportive Campus Environment & 0.37 & 0.34 \\
Supportive & 0.28 & 0.26 \\
Interpersonal & 0.37 & 0.33 \\
Support for learning & 0.26 & 0.24 \\
Satisfaction & & \\
Gains in Learning and Intellectual Development & & 0.42 \\
Gains - personal/social & 0.43 & 0.32 \\
Gains - general education & 0.34 & \\
Gains in Social Awareness & & 0.45 \\
Gains - Understanding diversity & & 0.34 \\
Gains - Contributing to community & 0.44 & 0.36 \\
Gains - Understanding self & 0.34 & 0.28 \\
Gains - Understanding others & 0.27 & 0.32 \\
\hline
\end{tabular}

Note: for all coefficients $\mathrm{p}<.001$

Note: Level 2 controls - urbanicity, sector, size, and selectivity

Level 1 controls - age, race, gender, transfer, grades, Greek, major, full-time, first-generation college student 
Figure 1. Senior structural diversity density by Carnegie Classification

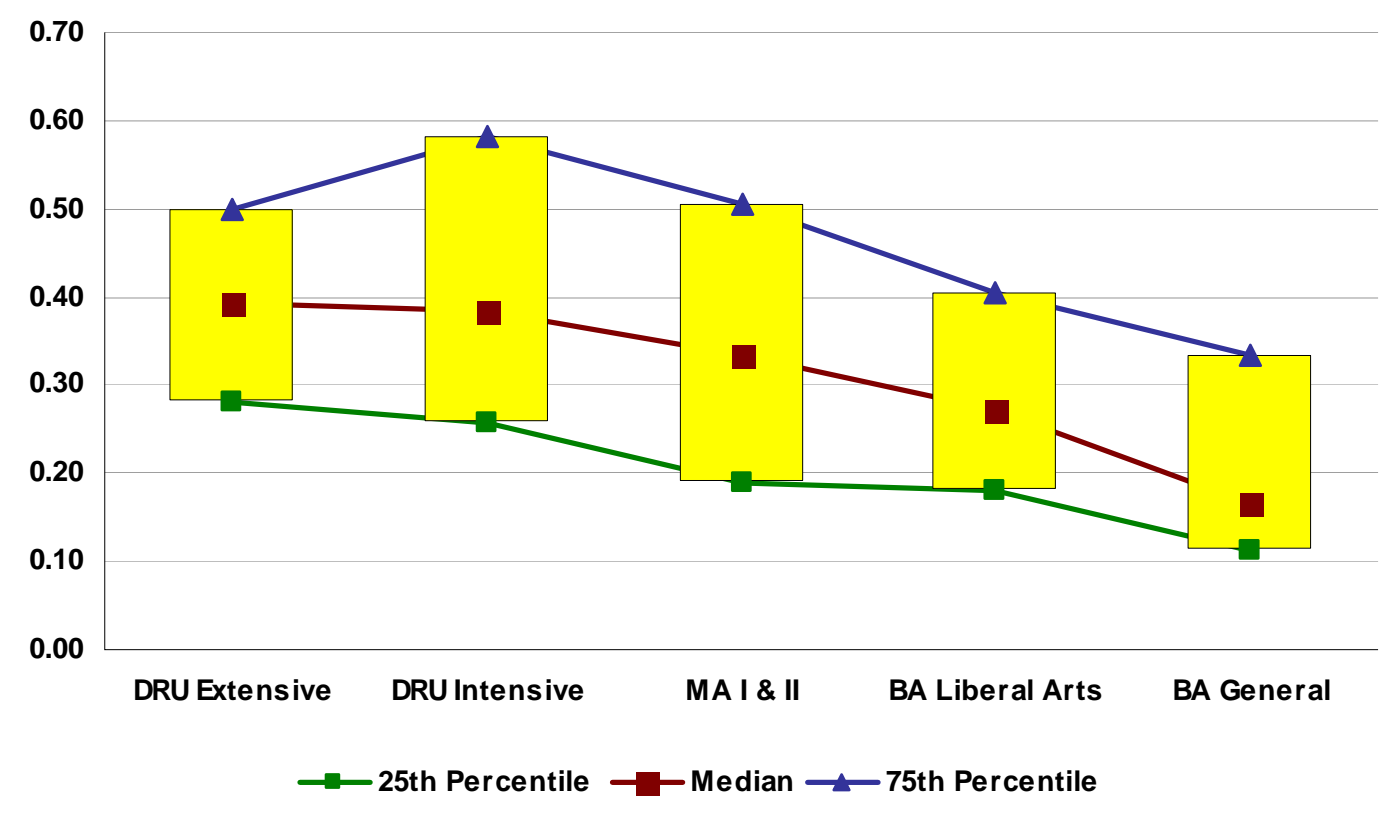

